\title{
De nuevo sobre los yangüeses del Quijote
}

\author{
Rafael Barroso Cabrera* \\ JoRge Morín de PABlos*
}

\section{LA EDICIÓN PRINCEPS Y LOS EPÍGRAFES DE LOS CAPÍTULOS X Y XV DEL QUIJOTE}

Desde prácticamente su publicación las diferentes ediciones del Quijote han intentado solventar las incoherencias que se dan entre los títulos de algunos capítulos y el texto de los mismos. Estas incongruencias entre epígrafes y cuerpo de texto se muestran particularmente evidentes en los capítulos X y $\mathrm{XV}$ de la primera edición de la novela cervantina, donde se narra el encuentro de Don Quijote con un grupo de arrieros que hacen el camino Real a Sevilla con su recua de mulas y sus mercancías. En esta primera edición del Quijote, publicada en Madrid en el año 1605, Cervantes utilizó en los epígrafes de ambos capítulos la referencia a ciertos arrieros yangüeses que curiosamente luego no volverán a aparecer más en el texto, donde se les cita siempre como gallegos.

La primera mención a los yangüeses figura en el epígrafe del capítulo X, que lleva el absurdo título "De lo que mas le auino a don Quixote con el Vizcayno, y del peligro en que se vio con una turba de Iangueses», título realmente insólito porque nada tiene que ver con el tema que desarrolla el capítulo, sino que trata de una serie de razonamientos cruzados entre Don Quijote y su escudero Sancho Panza ${ }^{1}$. El epígrafe resulta además del todo disparatado

* Departamento de Arqueología, AUDEMA.

1. Rodríguez Marín, Francisco, Quijote X 3, quien añade además: «En esto... se ve patente una nueva muestra del descuido de Cervantes y de que los epigrafes de los capitulos se añadieron ya escrita la obra, sin volver á leerla para ello siquiera con mediana atención.» Dicho error, por otra parte, no es el único de este tipo a lo largo de la novela: un descuido semejante hallamos en el epígrafe 
porque la aventura con el vizcaíno ya ha tenido lugar en el capítulo anterior y la de los arrieros no tendrá lugar hasta el capítulo XV. Esto ha dado pie a que en ediciones posteriores el título original del capítulo fuera sustituido por otros más acordes con el contexto de la narración. La Real Academia Española, por ejemplo, ya en su edición primera del Quijote del año 1780, sustituyó el incongruente epígrafe con otro semejante al de la edición de Tonson (Londres, 1738) y que se acerca más al argumento del capítulo. Con todo, la decisión de la Real Academia no ha sido aceptada de forma unánime por parte de ulteriores editores, los cuales, llevados quizá por un exceso de celo por la princeps, se han mostrado divididos en cuanto al criterio a adoptar con respecto al problema. Así, mientras la edición de J. E. Hartzenbusch para la Biblioteca Nacional (Madrid, 1821) mantuvo el título original, la Diego Clemencín y la de Ribadeneyra para la Biblioteca de Autores Españoles (Madrid, 1860), trocaron el título original por el más acertado de «De los graciosos razonamientos que pasaron entre D. Quijote y Sancho Panza», que es el que sigue Rodríguez Marín en su edición (Madrid, 1916).

El error es tan evidente que no han faltado intentos de explicación. Astrana Marín supuso que Cervantes comenzó a escribir en Toledo la continuación del Quijote desde el capítulo IX, dejando para después el engarce con la novela escrita en la cárcel sevillana y que, debido a las prisas de entrega de la novela al editor, el acoplamiento resultó defectuoso ${ }^{2}$. Según Riquer, este descuido es sumamente revelador por cuanto hace suponer que Cervantes había ideado que la aventura de los yangüeses viniera originalmente después de la lucha con el vizcaíno y que más tarde todo este material se reordenó de forma desacertada ${ }^{3}$. Y es que, en efecto, la inclusión del Discurso de la Edad de Oro y de la historia de Marcela y Grisóstomo - que en principio iba destinada al capítulo XXV-obligó a colocar el episodio de los arrieros en el capítulo $\mathrm{XV}$, desconectándolo del episodio del vizcaíno y haciendo aún más llamativo el error del epígrafe del capítulo X. Sobre ello habremos de volver más adelante cuando apuntemos una posible explicación a este desconcertante descuido, porque antes debemos tratar acerca de esa segunda mención a los yangüeses, mucho más explícita pero no menos problemática.

Como se ha dicho, no será hasta el capítulo XV, titulado «Donde se cuenta la desgraciada auentura que se topó don Quixote, en topar con unos desalmados Iangueses», cuando se narre la aventura tenida por Don Quijote con unos arrieros a cuenta de las ganas de Rocinante de solazarse con sus yeguas. El lector actual da por supuesto que estos arrieros eran yangüeses puesto que así lo dicta la titulación de los capítulos X y XV, y como tal aparece reflejado en la mayoría de las ediciones de la obra cervantina, que recogen la corrección

del capítulo XXXVI, que versa sobre la batalla con los cueros de vino, aventura que se ha narrado también en el capítulo anterior.

2. Astrana Marín, Luis, Vida ejemplar y heroica de Miguel de Cervantes Saavedra, Madrid, 1953, V, p. 440.

3. Riquer, Martín de, Don Quijote de la Mancha, Barcelona, Planeta, 1982, I, 10. 
hecha ya en la segunda edición del año 1605. Sin embargo, como decimos, la cuestión es algo más complicada de lo que a primera vista puede parecer.

Como se sabe, hasta 1776 la primera y segunda ediciones de Juan de la Cuesta fueron consideradas como una misma. En ese año, una carta de John Bowie a Thomas Percy señalaba la existencia de dos ediciones diferentes ${ }^{4}$. Entre las diferencias de las dos ediciones de 1605 se encuentra el error entre epígrafes y texto de los capítulos X y XV. Ya desde la segunda edición, impresa también en el taller de Juan de la Cuesta, dicho error aparece corregido en el texto, sustituyendo «gallegos» por «yangüeses», corrección que en adelante será la que haga fortuna y la que figure en la mayor parte de las ediciones de la novela.

No obstante, la que aquí nos interesa es la llamada edición A de 1605, es decir, la edición princeps (preparada ya para su impresión en diciembre de 1604, aunque lleve fecha del año siguiente) y, por tanto, la que cabe suponer más cercana al original cervantino. Esta edición mantiene una clara anomalía al mencionar en el título el origen yangüés de estos arrieros, mientras que en el texto se refiere a los mismos siempre como gallegos ${ }^{5}$. Esta discordancia se repite en todo el pasaje y hasta la fecha no ha sido convincentemente explicada, si bien, como suele suceder en estos casos, no han faltado autores que defienden la discordancia como algo buscado por el propio Cervantes. Esta defensa de la intencionalidad del descuido ha sido, sin embargo, contestada por otros investigadores. Francisco Rico, por ejemplo, se hace eco de ello en su edición del Quijote al decir que «en cambio, no creo que pueda tomarse en consideración la desesperada hipótesis de que se trata de burlas deliberadas de Cervantes o de incomprensibles guiños de complicidad al lector. Es inimaginable que los títulos con la mención de los yangüeses se redactaran inmediatamente antes de componer los capitulos en que de hecho figuran: todo indica que se insertaron posteriormente, en el curso de un proceso de reorganización de los materiales primitivos, y, por ende, suponen que Cervantes no recordaba que había hecho gallegos a los que ahora creía recordar como yangüeses (quizá porque estos le eran más familiares en cuanto arrieros) o bien denotan la intención de introducir en el libro modificaciones y retoques que no llegaron a realizarse (si, por ejemplo, hacas galicianas quería significar "resabiadas y falsas", Cervantes pudo pensar que el matiz se perdería dando por gallegos a los arrieros)». Por esta razón, Rico concluye que esta discordancia tuvo que ver con los cambios de última hora introducidos por el propio Cervantes en el original y que llevaron a confusión al editor. Con todo, el autor es consciente de que es imposible saber si Cervantes tuvo que ver con la corrección que trae la edición $\mathrm{B}^{6}$. Del mismo modo, al referirse al error

4. Rico, Francisco, D. Quijote de la Mancha, Miguel de Cervantes, Madrid, Instituto Cervantes, 1998, n. Portada.

5. Rico, Francisco, El texto del Quijote. Preliminares de una ecdótica del Siglo de Oro, Barcelona, Destino, 2005, p. 233, n. 58.

6. Rico, Quijote, I 15160.3. 
del epígrafe del capítulo XXXVI, error semejante al del capítulo X, el citado autor observa: «un error de esa índole sólo puede responder a la intercalación de títulos en un texto que no los llevaba, a una nueva distribución de ese texto en capítulos o bien a un desplazamiento de alguna o algunas secciones a otra parte del original» ${ }^{7}$. Como veremos esta cuestión es fundamental para adivinar la autoría del cambio de gallegos por yangüeses en la novela.

Esta misma opinión mostraba Martín de Riquer, quien, después de advertir una vez más la incoherencia entre título y texto en la edición A, afirma en la correspondiente nota al epígrafe que «A partir de la segunda edición del Quijote los arrieros dejan de ser gallegos para ser siempre yangüeses, sin que se pueda afirmar categóricamente que este cambio se deba a Cervantes, el cual, de todos modos, aceptó la denominación, pues Sancho en la segunda parte, menciona "la aventura de los yangüeses" (II 3) $\rangle^{8}$. Como puede verse, por tanto, también para Martín de Riquer existen serias dudas de que el cambio fuera efectuado por el escritor, hasta el punto que considera que la referencia a unas «hacas galicianas» (jacas gallegas) es un apoyo a la tesis de que los arrieros fueran originalmente gallegos, por lo que en su edición del Quijote se limita a señalarlos como tales según trae la princeps. Y eso a pesar de incurrir en una clara contradicción en su edición de la novela, porque, como se ha dicho anteriormente, admite que Cervantes aceptó finalmente el cambio en la segunda parte ${ }^{9}$. Muy al contrario, por esta última razón, Francisco Rico discrepa de la decisión de los editores que, como hemos visto en el caso de M. de Riquer, mantienen el texto tal como figura en la edición princeps, justificándose precisamente en que «en II, 3, 649, al referirse a «la aventura de los yangüeses», el escritor dio por válido el texto de B; y, frente a la moderna tendencia... a reproducir ciegamente la lección de la príncipe, es preciso respetar esa última manifestación de su voluntad al propósito» ${ }^{10}$.

En cualquier caso, la vacilación entre gallegos y yangüeses se remonta a todas las ediciones de 1605, donde la corrección del error o descuido se alterna indistintamente con el texto original de la edición princeps. Aparte de las dos ediciones madrileñas de 1605 de Juan de la Cuesta ya referidas, la indecisión se observa en las ediciones de Lisboa y Valencia de ese mismo año. Así, mientras las ediciones impresas en Lisboa a cargo de Jorge Rodríguez y Pedro Crasbeeck reproducen el error de la edición princeps, la de Valencia, debida a Pedro Patricio Mey, corrige el texto del capítulo XV adecuándolo al título tal como aparece en la edición B de Juan de la Cuesta.

7. Ibíd., I 36 424.2.

8. Riquer, Quijote, I 15.

9. Ibíd., loc. cit.

10. Rico, Quijote, I 15. 160.3 . 


\section{LOS YANGÜESES DEL QUIJOTE}

Antes de seguir con este problema conviene decir algo sobre los protagonistas del episodio. Prácticamente todos los editores modernos de la novela cervantina se han hecho eco de la existencia en España de dos localidades con el nombre de Yanguas. La primera se halla en la comarca del Camero Viejo, al norte de la provincia de Soria, aunque antiguamente perteneciera al obispado de Calahorra y La Calzada. La segunda, llamada Yanguas de Eresma, se encuentra en la provincia de Segovia. Aunque casi ninguno de los editores consultados se pronuncia claramente sobre cuál de estas dos localidades es el origen de los arrieros del Quijote, parece existir un cierto consenso entre los investigadores en que la patria de los arrieros cervantinos es la villa soriana. Se aducen para ello dos importantes razones: la primera y principal, porque a los moradores de esta villa les fue otorgado en 1347 un privilegio de portazgos que les eximía del pago de los impuestos de peaje en prácticamente todo el reino de Castilla. La segunda, es que, como punto de arranque de la Cañada Oriental Soriana, la villa soriana era cabecera de una de las principales rutas de la trashumancia ganadera que coincide parcialmente con el itinerario seguido por el Quijote ${ }^{11}$.

El privilegio de portazgos se remonta al reinado de Alfonso XI (13121350). Durante la primera mitad del siglo XIV la Comunidad de Villa y Tierra de Yanguas, como otros muchos territorios de la montaña castellana, se encontraba inmersa en una profunda crisis económica que obligó al citado monarca a adoptar medidas excepcionales con objeto de evitar el despoblamiento de la zona. En este contexto, en el año 1347 Alfonso XI decidía otorgar a los habitantes de la tierra de Yanguas el conocido privilegio de portazgos que les concedía la exención de pagar ese oneroso impuesto en todas las ciudades del reino con la excepción de Toledo, Sevilla y Murcia. El privilegio fue periódicamente renovado por los reyes de Castilla: en las cortes de Medina del Campo de 1370 y en las de Toro de 1371, bajo el reinado de Enrique II; en las de Burgos de 1379 con Juan I y en las de Madrid de 1393, bajo Enrique III. El privilegio de portazgos eximía a los yangüeses del pago de peajes en caminos y ciudades, y constituyó, junto a la pujanza de la cría de ganado ovino impulsada por la Mesta y el comercio atlántico, el inicio de un extraordinario despegue económico de la comarca. Dicha expansión económica queda puesta de manifiesto en la acometida de multitud de obras constructivas en toda la tierra yangüesa y, de modo muy singular, en la propia villa. Entre estas

11. Klein, Julius, The Mesta. A Study in Spanish Economic History 1273-1836, Cambridge Mass., 1920, p. 19; Toledo Toledo, Manuel, Historia de la Villa y Tierra de Yanguas. Soria, 1995, p. 142; Navarro Blázquez, Alfonso, Ruta del Quijote en Sierra Morena, Memoria de Grado, dir. Manuel Fernández Nieto, Facultad de Filología, Universidad Complutense de Madrid, 2007; Valdecantos, Diego, «Sobre el Quijote», Yanguas, 2005, pp. 13-14. Sólo D. Clemencín aventura que se trata de los naturales del pueblo homónimo segoviano: Clemencín, D., Quijote, XV, p. 3, opinión que sigue Rodríguez Marín, F. Quijote, XV, p. 439. 
construcciones cabe citar el castillo de los condes de Aguilar, un magnífico puente sobre el río Cidacos, ambos en el siglo XIV, y sobre todo la gran obra de la iglesia de Santa María, iniciada a finales del siglo XV y que tendrá una importante reforma contemporánea a la edición del Quijote ${ }^{12}$.

Paralela a esta expansión económica y en relación con la instalación en Yanguas de la corte de los condes de Aguilar se documenta asimismo un cierto desarrollo cultural de la mano del humanista Hernán López de Yanguas (1487¿?), autor al que se deben varias obras dramáticas (Farsa Turquesana; Farse de la Concordia; Triunfos de la Locura) y humorístico-didácticas (Diálogo del mosquito; Dichos de los Siete Sabios de Grecia en metro) y considerado por algunos precursor de los autos sacramentales por su obra Farsa sacramental en coplas, impresa en $1520^{13}$. Es muy posible que el dramaturgo sea el mismo Hernán López que figura como beneficiario y cabezalero (albacea) en el testamento del bachiller Juan Sáenz de los Arcos de $1547^{14}$. Contemporáneo de Hernán López de Yanguas es otra figura señalada de las letras del XVI: Antonio de Oncala u Honcala (1484-1565), discípulo que fue de Antonio de Nebrija y amigo personal de Juan Martínez de Silíceo, preceptor del príncipe. Antonio de Oncala llegó a impartir clases en la Universidad de Salamanca - donde alcanzaría a ser miembro destacado del claustro - y canónigo magistral de la catedral de Ávila. Fue, además, autor de varias obras gramáticas y teológicas de cierto interés, entre ellas el Pentaplon Cristianae Pietatis, célebre obra porque en ella se encuentra la primera redacción escrita del milagro de la Cruz de Caravaca. Su apellido lo hace oriundo de la tierra (Oncala es, en efecto, una villa perteneciente a las tierras altas sorianas) como él mismo se encarga de certificar en el título de una de sus obras más relevantes: los Comentarios al Génesis, obra titulada originalmente Comentaria in Genesim Antonio Honcala Ianguensi Theologiae Doctores Abulensi Ecclesiae Canonico... impresa en Alcalá de Henares en $1555^{15}$.

Gracias al privilegio de portazgos los yangüeses llegaron prácticamente a monopolizar el tránsito de mercancías entre Sevilla y el norte cantábrico, dando lugar a una ruta comercial que ha sido llamada con razón «camino de los yangüeses». En la España del siglo XVII el yangüés fue reconocido como transportista eficaz y de probada fidelidad, siendo así que su figura fue

12. Klein, op. cit., p. 183; Delgado Martínez, M. ${ }^{a}$ Consuelo, Apuntes sobre la vida rural de la Villa y Tierra de Yanguas (Soria). Siglos XII-XVI, Centro de Estudios Sorianos, CSIC, 1981; Toledo, op. cit., pp. 45-52.

13. Fernán López de Yanguas, Obras dramáticas, Ed. F. González Ollé, Madrid, Espasa-Calpe, 1967. Varias obras de este autor son accesibles a través de internet: Farsa Turquesana (1529?) ed. Julio F. Hernando y Javier Espejo, 2002; Triunfos de Locura. El Diálogo del Mosquito está reproducido en Toledo, op. cit., pp. 67-78.

14. Toledo, p. 118.

15. Para Antonio de Oncala vid. Beltrán Heredia, Vicente, Cartulario de la Universidad de Salamanca (1218-1600), Tomo II, Acta Salmanticensia 19, Universidad de Salamanca, 1972, quien lo describe como «hombre estudioso, pero de escasa capacidad» (p. 554) y De la Fuente Adánez, Alfonso, Una exégesis para el siglo XVI: Antonio de Honcala (1484-1565) y su Comentario al Génesis, Biblioteca salmanticensis: Estudios, vol. 167, Salamanca, Universidad Pontificia, 1994. 
determinante para mantener viva la comunicación entre ambos extremos de la península, como se demuestra en la conducta o conducción de plata desde Sevilla a las villas vascongadas: más del 75\% de las mercancías salidas del puerto hispalense entre 1650 y 1675 lo hicieron por mano de yangüeses. Estamos hablando de un material precioso, no sólo por su valor intrínseco (plata), sino porque muchas veces se trataba de objetos de orfebrería de gran riqueza artística y, además, de hondo sentido espiritual (por tratarse en su mayor parte de crucifijos y otros objetos religiosos) y, por tanto, de piezas que tenían un gran valor sentimental para sus posesores ${ }^{16}$. Si tenemos en cuenta la gran responsabilidad que este tráfico de obras supone, y el hecho de que los transportistas cobraban una parte muy reducida del valor de la operación, podemos juzgar en sus justos términos la excelente reputación de que disfrutaban los arrieros y carreteros yangüeses en su época.

No nos parece imposible que en este punto los yangüeses se vieran favorecidos por su origen mixto riojano-navarro, lo que abre la posibilidad de que hubiera entre sus filas un buen número de hablantes de lengua vascongada. La presencia de gentes vasconas en el área del alto Cidacos es una constante histórica que se remonta nada menos que al siglo I d.C., como atestigua un grupo epigráfico de características propias y onomástica vasco-aquitana ${ }^{17}$. Siglos después, en la Edad Media, la Tierra de Yanguas pasó a pertenecer al dominio de los Banu Qasi, clan muladí emparentado con los primeros reyes de Pamplona, siendo más tarde anexionada al reino de Pamplona-Nájera hasta que, ya en 1134, durante el reinado de Alfonso VII (1105-1157), se incorporó definitivamente al reino de Castilla. A partir de esa fecha hasta el reinado de Alfonso XI (1312-1350) el territorio quedó sometido al Señorío de los Cameros, uno de los principales de la corona castellana ${ }^{18}$. No es extraño, por tanto, que en la documentación sobre Yanguas y su tierra abunden los apellidos de origen vasco-navarro (Aguirre, Ochoba, Zaldívar, Vidorreta, Yturriaga, Salazar, Usategui, etc. $)^{19}$, fenómeno que se ha mantenido incluso en nuestros días. La extraordinaria abundancia del apellido Sáenz/Sánchez en la onomástica yangüesa —el más usado con diferencia en cualquiera de sus variantes - también es un dato a tener en cuenta, pues, como señala F. Rico a propósito del vizcaíno Sancho de Azpeitia, el nombre de Sancho «es proverbial de vizcaínos» ${ }^{20}$.

16. Quiles, Fernando, De yangüeses y otra gente en la conducta de plata (Sevilla, 1650-1675), en J. M. Almansa et al. (eds.), Actas del II Congreso Internacional del Barroco americano. Territorio, Arte, Espacio y Sociedad, Sevilla, 8 a 12 de octubre de 2001; Azpiazu, José Antonio, «Los guipuzcoanos y Sevilla en la Alta Edad Moderna», Itsas 4, San Sebastián, 2003, pp. 207-225.

17. Espinosa Ruiz, Urbano y Usero, Luis M., «Eine Hirtenkultur im Umbruch. Untersuchungen zu einer Gruppe von Inschriften aus dem conventus Caesaraugustanus (Hispania Citerior)», Chiron 18, 1988, pp. 477-504.

18. Camporredondo, Luis, Miscelánea. Recuerdos de Yanguas, Soria, 1934, pp. 31-34; Delgado, op. cit., pp. 47-55; Toledo, op. cit., pp. 45-52.

19. Quiles, art. cit. passim.

20. Rico, Quijote, I 9 36. Tal vez haya que ver en esta doble relación entre vizcaínos y yangüeses - el camino seguido por el cortejo de la dama vizcaína hacia Sevilla se corresponde con el itinerario 
Como se ha adelantado unas líneas más arriba, además del privilegio de portazgos otra de las razones que apunta a la identificación de los yangüeses del Quijote con los habitantes de la montaña soriano-riojana es que la tierra de Yanguas era cabeza de una de las principales cañadas trashumantes de la península: la Cañada Real Soriana Oriental. Esta cañada partía de las tierras altas sorianas y atravesaba la península de norte a sur por las actuales provincias de Guadalajara, Madrid y Toledo hasta llegar a los ricos pastos invernales de los valles de Alcudia (Ciudad Real) y Los Pedroches (Córdoba), prosiguiendo después su camino hasta Sevilla. De hecho, el camino transitado por el hidalgo manchego en la primera parte se corresponde con notable exactitud con la ruta seguida por los yangüeses en sus idas y venidas a lo largo de la meseta hasta el valle del Guadalquivir ${ }^{21}$, si bien posteriormente el itinerario del hidalgo manchego se desvía para seguir la cañada de Aragón y Cuenca ${ }^{22}$. Es muy posible que los arrieros yangüeses se beneficiaran del entramado de vínculos sociales y económicos que sus parientes pastores trashumantes habrían tejido alrededor de las poblaciones que atravesaban en su vagar hacia tierras meridionales.

La imagen de los arrieros y ganaderos yangüeses desplazándose con sus caballerías a través de La Mancha siguiendo la ruta de la Cañada Soriana Oriental era sin duda una estampa familiar para los castellanos de los siglos XIV-XVII, sobre todo en este último siglo, cuando puede hablarse en propiedad de un verdadero monopolio yangüés de la ruta comercial terrestre que comunicaba la pujante Sevilla con las villas vascongadas. La celebridad de los yangüeses aumentaría también gracias a los numerosos pleitos entablados en defensa de su exención tributaria. De ello da fe la larga serie de procesos sostenidos durante años contra los agentes municipales perceptores de portazgos y las autoridades que insistían en incumplir el mandato regio: entre los años 1500 y 1660 existe una multitud de sentencias expedidas por las Reales Chancillerías de Valladolid o Granada favorables a las demandas de los yangüeses, algunas de ellas frente a personajes tan poderosos como el Condestable de Castilla, el arzobispo de Toledo, el Almirante de Castilla o la Orden de Calatrava. Precisamente esta reiterada defensa de su privilegio debió granjearles una mala fama entre ciertos sectores del reino, formándose una imagen estereotipada del yangüés como gente litigante y polémica ${ }^{23}$.

Evidentemente a comienzos del XVII resultaba mucho más popular y comprensible para el lector castellano la sustitución de los originales arrieros gallegos que trae la princeps por los mucho más célebres arrieros yangüeses de la segunda edición. Se ha defendido que esta corrección fue realizada por el propio Cervantes, quien, por su condición de recaudador de impuestos,

de los yangüeses y el hecho de que éstos actuaban como intermediarios comerciales con los vizcaínos - la idea, más tarde abandonada, de colocar juntos ambos episodios, lo que daría lugar al error del epígrafe del capítulo X.

21. Navarro Blázquez, op. cit.

22. Klein, op. cit., p. 19, nt. 2.

23. Toledo, op. cit., p. 51. 
habría tenido algún tipo de relación directa con los yangüeses y estaría de algún modo familiarizado con ellos ${ }^{24}$. Pero, dejando a un lado que no existe constancia documental de esa pretendida relación entre el escritor y los yangüeses, no se comprendería entonces por qué razón no hizo alusión a ellos en la primera redacción conocida del Quijote, más aún cuando los epígrafes de los capítulos X y XV de la edición príncipe mencionaban explícitamente a los yangüeses como protagonistas del episodio, incluso aun cuando ni siquiera aparezcan mencionados en el texto, como ocurre con el capítulo X.

Una hipotética relación entre yangüeses y Cervantes señala Isidro Cabello a partir de un episodio sucedido en 1592 entre un grupo de arrieros yangüeses que trataban de eludir el pago de la alcabala y don Pedro Ramírez de Arellano, conde de Aguilar y señor de Yanguas. Don Pedro era pariente de don Alonso López de Zúñiga, duque de Béjar, a quien va dedicada la primera parte del Quijote. Según este autor, el episodio sería conocido por Cervantes, quien, entre 1587 y 1600 , era alcabalero en Andalucía y lo introdujo en su novela, eso sí, cambiando la patria de los arrieros para no ofender al duque de Béjar, pariente del conde de Aguilar. Cabello supone, pues, que fue el propio Cervantes quien realizó la sustitución, primero de yangüeses a gallegos para no ofender a su protector, el duque de Béjar, y luego de gallegos a yangüeses, una vez que, al haber olvidado corregir el texto de los epígrafes en la edición A, quedaba manifiesta la alusión al suceso protagonizado por el conde de Aguilar $^{25}$.

No obstante, es difícil pensar que se corrigieran las alusiones del texto y no las de los epígrafes, siendo aquéllas más numerosas y complicadas desde el punto de vista de la impresión. Además, esto supondría tres cambios desde el manuscrito al texto impreso (primero yangüeses en el manuscrito, luego gallegos y finalmente yangüeses otra vez) y todo ello en muy poco espacio de tiempo. Eso sin contar que la presunta alusión a los yangüeses en el manuscrito no deja de ser una hipótesis sin prueba documental.

A nuestro juicio, esta interpretación descansa sobre la idea anacrónica de un Cervantes que domina la totalidad de su obra sin tener en cuenta los complejos mecanismos de edición de textos que se daban en el Seiscientos. En realidad, tal como defendió M. de Riquer, parece harto improbable concluir que esta indicación a los arrieros yangüeses pudiera ser obra del mismo Cervantes a tenor de que su primera aparición se da en los epígrafes y no en el cuerpo del texto. Más bien sugiere, por el contrario, que la intención original del escritor no era otra que incidir en el juego humorístico que suponía el equívoco sentido de «hacas galicianas» como «jacas gallegas» y como «resabiadas», y que sólo más tarde cambió su opinión aceptando el cambio de «gallegos» por «yangüeses» que aparece en los epígrafes debido a la fama de éstos como arrieros y, quizá, como pleiteadores. Dicho en otras palabras,

24. Valdecantos, art. cit.

25. Cabello Hernandorena, Isidro, «El Quijote y La Rioja: el episodio de los yangüeses», Belezos: Revista de cultura popular y tradiciones de La Rioja 16, 2011, 49-55. 
todo hace pensar que el cambio de los epígrafes no fue obra del escritor, sino que fue introducido por alguien relacionado con las tareas de composición del libro.

\section{LOS DESCUIDOS CERVANTINOS}

Con esto entramos aquí en la difícil cuestión de los «descuidos cervantinos». Como se sabe, se denominan «descuidos cervantinos» a una serie de errores que pueden hacer que un personaje entre en contradicción consigo mismo, que el tiempo y el espacio se distorsionen o que un episodio ignore la existencia de otro anterior. Existen, pues, diversos tipos de descuidos cervantinos - hasta cuatro clases identifica Martín Morán ${ }^{26}$ _, cuya explicación sigue siendo materia de discusión entre los especialistas, pero de los que aquí sólo nos interesará uno: las incongruencias entre epígrafes y texto como las que se dan en los capítulos X y XV.

Como afirma Martín Morán, la crítica ha solido prestar poca atención a los descuidos cervantinos, todo lo más se ha limitado a señalarlos pero sin tratarlos a fondo. Este desinterés resulta cuando menos curioso porque desde finales del siglo XVIII y a lo largo del XIX hubo una larga polémica sobre este tema. Para Martín Morán, la falta de interés por el tema en nuestros días es proporcional a la revalorización del papel de Cervantes como autor consciente de su obra. Curiosamente este desinterés por los descuidos cervantinos ha supuesto en la práctica el desconocimiento de un fenómeno que puede ofrecer información muy valiosa acerca de la técnica narrativa de Cervantes y de la forma cómo se componían los libros en el Siglo de Oro, tema que sólo se ha visto paliado a raíz de la publicación del estudio que Francisco Rico dedicó a este tema hace pocos años ${ }^{27}$.

Los estudiosos de la obra de Cervantes se han dividido a la hora de juzgar estos descuidos. Para los que piensan que el Quijote es una obra superior a su autor (los llamados «quijotistas»), se trata de una prueba de la inconsciencia del autor. En el polo opuesto se hallan los «cervantistas», es decir, los que, defendiendo al autor por encima de su obra, suponían que estos errores van en menoscabo del genio de Cervantes y, por lo tanto, se soslayaban o se le dispensaban, bien en razón de su cargo como atareado recaudador de alcabalas, o bien por las prisas motivadas por el deseo de anticiparse a la segunda parte del Guzmán de Alfarache o para contrarrestar los efectos del Quijote de Avellaneda. La explicación de este fenómeno no sería otra que las prisas en la redacción y la precipitación con que Cervantes escribió su obra ${ }^{28}$. En los

26. Martín Morán, José, El Quijote en ciernes y las fases de elaboración textual, Turín, ed. Dell'Orso, 1990.

27. Rico, Francisco, El texto del Quijote. Preliminares de una ecdótica del Siglo de Oro, Barcelona, Destino, 2005.

28. Martín Morán, op. cit. 
últimos años, sin embargo, han surgido voces discordantes que postulan la intencionalidad de estos aparentes errores, ya sea como ejercicio de imitación de las novelas de caballerías ${ }^{29}$ o como descuidos deliberados que forman parte de la literalidad textual ${ }^{30}$.

Sea como fuere, los trabajos de Martín Morán, Lathrop y Molho son un reflejo de una creciente revalorización de la importancia que tienen estos descuidos de cara a la comprensión de la obra en sí, en la medida que su estudio permite un ejercicio filológico de búsqueda del arquetipo del texto original - lo que se ha dado en llamar «Protoquijote»_, y en esta misma línea debe enmarcarse nuestro estudio. La búsqueda de este prototipo se ha convertido en una obsesión para muchos estudiosos de la obra de Cervantes, de manera que se han lanzado todo tipo de hipótesis y teorías acerca de cómo pudo ser ese controvertido Ur-Quijote: novela corta más tarde ampliada, yuxtaposición de narraciones inconexas, etc. La hipótesis que aquí defendemos tiene que ver con el proceso de composición del libro, no como obra literaria propiamente dicha, sino como objeto de venta al público, y puede ayudar a comprender un poco más el proceso de creación del Quijote en cierto modo como obra colectiva, en tanto que obra destinada a la venta, y romper así definitivamente con el tópico del escritor solitario que retiene para sí todo el control sobre su obra.

\section{El PROCESO DE ELABORACIÓN DEL QUiJOTE}

Dada la incongruencia que existe entre epígrafe y narración en los capítulos $\mathrm{X}$ y XV, cuesta trabajo creer que Cervantes pudiera incurrir en tamaño error. En realidad, como resalta F. Rico, resulta inimaginable que los títulos con la mención de «yangüeses» se hubieran redactado inmediatamente antes que el texto. Ya hemos visto también cómo M. de Riquer se mostraba receloso acerca de la autoría cervantina de este cambio. De opinión muy diferente es $\mathrm{T}$. Lathrop, quien hace unas décadas planteó la hipótesis de que este error, como otros muchos que aparecen en el Quijote, no es sino una imitación del estilo de los libros de caballería a los que Cervantes pretendía parodiar ${ }^{31}$.

Parece evidente que la clave de todo este asunto descansa precisamente en el método de composición del Quijote. En los últimos años la visión romántica de una redacción del texto debida exclusivamente a Cervantes - bajo la que subyace la idea anacrónica del dominio del autor sobre la totalidad de su obra - ha dejado paso a una visión más compleja del proceso de redacción que abre nuevas vías para una correcta comprensión de la obra literaria. El mismo Lathrop señala que errores del tipo al que aquí se estudia se daban también con

29. Lathrop, Thomas A., «Las contradicciones del Quijote explicadas», AIH Actas X, 1989, pp. 635-639.

30. Molho, Maurice. «¿Olvidos, incoherencias? o ¿Descuidos calculados? (Para una lectura literal de Don Quijote)», AIH Actas X, 1989, pp. 653-660.

31. Lathrop, art. cit., pp. 638-639. 
frecuencia en los libros de caballerías, y que esto era debido a que más de una persona participaba en la producción de los manuscritos, siendo habitual que una persona escribiera el texto y otra distinta - a veces con desconocimiento de lo que pasaba en el capítulo- hacía lo propio con los epígrafes.

En realidad, en tiempos de Cervantes el escritor no era el único que desempeñaba un activo papel en la confección del texto. Participaban de esta tarea un buen número de profesionales bajo una dirección técnica. Las modificaciones, sugerencias e interpolaciones al texto original por parte de personas ajenas a la pura creación literaria (desde el escribano o amanuense que copiaba el original para sacar un «original de imprenta», al impresor que distribuía los capítulos y ordenaba cómo encajar el texto o el corrector de pruebas y los tipógrafos y componedores que regularizaban la puntuación y ortografía, así hasta un sinfín de manos) eran materia frecuente en los libros del Siglo de Oro y un hecho consumado tácitamente aceptado por los escritores de la época $^{32}$. Como comenta F. Rico a propósito de esta cuestión «"El primor del oficio" otorgaba entonces al editor y al impresor un espacio de libertad y una capacidad de decisión que en la actualidad puede chocar» ${ }^{33}$. De ahí que muchas de esas incoherencias señaladas en el texto primitivo se deban entender no tanto como descuidos del propio escritor sino como accidentes en el proceso de transmisión del Quijote $^{34}$. En una época en que la fijación del texto definitivo correspondía más a los técnicos de imprenta que al escritor, resulta del todo imprescindible distinguir entre «libro» y «obra literaria»: el primero, como obra artesana objeto de venta, y el segundo, como creación literaria propiamente dicha destinada a la lectura.

Por esta razón sorprende que, en el caso de los descuidos relativos a epígrafes y texto, Lathrop llegue a la conclusión inversa a la que, obviamente, debía haber sido la más lógica. En su ánimo de exculpar a Cervantes («el autor más grande de todos los tiempos») y a su obra ("la obra maestra de todos los tiempos», «la obra más perfecta de todos los tiempos») de cualquier error, Lathrop, tomando partido en el bando "cervantista», considera que Cervantes preparó tanto los epígrafes como el texto de forma deliberadamente descuidada, como imitación de las equivocaciones que se podían ver habitualmente en los libros de caballerías ${ }^{35}$. Sin embargo, contrariamente a esta opinión, lo lógico habría sido plantear la cuestión en términos diametralmente opuestos: si estos errores eran frecuentes en los libros de caballería por la manera en que éstos se componían ¿por qué habría de extrañar que errores semejantes se produjeran también en una obra como el Quijote? En realidad, como afirma J. Canavaggio, muchos de los errores, olvidos y descuidos censurados en otro tiempo como desafíos del autor a su lector deben ser devueltos del autor a la imprenta ${ }^{36}$.

32. Rico, op. cit.

33. Ibíd., p. 150.

34. Canavaggio, Jean, «Reseña a Francisco Rico. El texto del "Quijote”. Preliminares a una ecdótica del Siglo de Oro», Criticón 99, 2007, 243-251.

35. Lathrop, art. cit., p. 635.

36. Canavaggio, art. cit., 245. 
En efecto, F. Rico ha señalado el importante papel que desempeñaba el impresor en la confección de la obra final, sobre todo en aspectos tales como la división en capítulos y la titulación de los mismos. En modo alguno significa esto que el Quijote sea una gran obra literaria chapuceramente editada. Errores como éste no son imputables, sin embargo, a una falta de profesionalidad de la imprenta de Juan de la Cuesta, sino a un modo de proceder que era común en la época y que, como todo método, tiene sus deficiencias. No obstante, a pesar de los numerosos errores que tienen las ediciones del Quijote debidas a Juan de la Cuesta, éste no era en modo alguno un ignorante en su oficio como a veces se ha sostenido injustamente, tal como con razón se lamenta D. Eisenberg $^{37}$. El problema, apostilla este autor, es que se ha juzgado la forma de trabajar de un editor del siglo XVII con parámetros propios del siglo $\mathrm{XX}^{38}$.

Todo ello plantea la posibilidad de que el cambio que motiva nuestro artículo no se debiera tanto a Cervantes, sino al impresor, Juan de la Cuesta o alguien de su círculo más inmediato, que tuviera la responsabilidad de realizar la división y titulación de los capítulos de la obra. Como es notorio, desde la segunda edición de 1605 Cervantes aceptó ya el cambio introducido por su impresor por el motivo aducido anteriormente, a saber, la fama de los arrieros de los yangüeses en el reino de Castilla que él mismo, como recaudador de alcabalas, debía conocer de primera mano. Como prueba de esa aceptación por parte del escritor, en la segunda parte del Quijote, se menciona «la aventura de los yangüeses» (II 3).

La cuestión que nos asalta es si fue esta imagen popular el único motivo que indujo al impresor a corregir el texto original o si hubo, por el contrario, alguna otra razón que influyera en un cambio tan significativo de protagonistas. Sin duda, la imagen de los arrieros yangüeses trajinando por España de norte a sur fue el motivo principal de su inclusión en el Quijote, pero creemos, además, que existió otra poderosa razón de tipo personal que pudo impulsar a Juan de la Cuesta a insertar a los arrieros yangüeses novela de Cervantes.

\section{Probable origen yangüÉs de JuAn de la Cuesta}

Apenas se conocen datos biográficos referidos al impresor del Quijote, si bien se sabe con seguridad que Juan de la Cuesta era yerno de María Rodríguez de Rivalde, viuda de Pedro Madrigal, y que actuó como regente de la imprenta que ésta tenía en propiedad entre los años 1599 y 1607 . En realidad, como señala F. Rico en su edición para el Instituto Cervantes, Juan de la Cuesta no

37. Eisenberg, Daniel, «On editing Don Quixote», Cervantes 3.1, 1983, pp. 23-24.

38. "What is clear, however, is that Cuesta was not an ignorant fool, negligent in his handling of Cervantes' manuscript, but a thoughtful man who had some stature as an expert on writing, spelling, and other accidentals. In fact, the printer-publishers, in Golden Age Spain as elsewhere, were men of some culture, not exactly the passive recipients of authors' initiative and slaves of public taste that they are often presumed to be», ibíd., pp. 28-29. 
tuvo más responsabilidad en el Quijote que la meramente tipográfica. Hay que entender aquí como tal la dirección de los trabajos de impresión en contraposición a la labor de edición del libro, que fue responsabilidad de Francisco de Robles, pues fue este último quien firmó el contrato con el autor, decidió la tirada, compró el papel, pagó el trabajo de composición e impresión, etc. Al menos hasta 1615, año en que edita la segunda parte del Quijote, Cervantes siguió publicando sus libros a costa de Robles, colaborando editorialmente y teniendo tratos económicos y personales con él ${ }^{39}$.

Eisenberg tratando de averiguar algo más sobre el oscuro pasado del impresor, reparó en que el de Juan de la Cuesta no es un nombre común ${ }^{40}$. Para nuestro caso interesa advertir que se trata de un apellido toponímico que sugiere un probable origen yangüés del personaje: La Cuesta es, en efecto, una pequeña población soriana situada en la Tierra de Yanguas que, aunque en la actualidad se halla casi totalmente despoblada, hacia comienzos de la Edad Moderna constituía uno de los principales centros ganaderos de la comarca yangüesa. Para hacerse una idea de la importancia económica de esta villa en este periodo baste decir que en esta población tenía su asiento la importante familia de los Rico, de la cual se sabe que mandó construir un gran caserón capaz de albergar más de 5.000 ovejas $^{41}$.

Los apellidos toponímicos eran frecuentes en la época y relativamente usuales en la documentación sevillana que registra los envíos de plata americana a tierras vascongadas a través de arrieros yangüeses donde abundan los apellidos alusivos a Yanguas y sus aldeas (del Cardo, La Mata, etc.) ${ }^{42}$. Más frecuentes son aún, lógicamente, en la documentación de la propia tierra yangüesa. Sendas relaciones de alcaldes de la Villa y Tierra y otra de hidalgos registran un gran número de apellidos del tipo patronímico+toponímico relacionados con núcleos de población de la comarca camerana. Sin ánimo de ser exhaustivos en la relación, entre 1459 y 1537 pueden citarse los alcaldes: Juan González de las Diustes (1472), Gil Martínez de Camporredondo (1468/70; 1517), Gil Martínez de Valdecantos (1491/1497), Pedro Martínez de Vellosillo (1496/1498), Juan Sánchez de Camporredondo (alcalde varios años entre 1475 y 1536), Juan Sánchez de las Diustes (1491 y 1503/1504), Sebastián Sánchez de Vellosillo (1531), Diego Sánchez de Valdecantos (1469, 1508), Pedro Sánchez de Yanguas (1514). Entre los hidalgos de la Villa y Tierra sucede otro tanto: Sáenz de Lería, Gil de Vega, González de Vega, Saenz de Villosillo (sic), de la Matha (sic) del Villar, de Lamata (sic) del Villar, Ruiz de San Andrés, Jiménez del Villar de Maya. Entre los oficiales públicos sucedía otro tanto, contándose los herreros Juan Marín de La Mata, Diego Ochoba de Diustes. Un tal Diego Pérez de La Cuesta figura como

39. Rico, op. cit., nt. (Portadas).

40. Eisenberg, art. cit., 25.

41. Toledo, op. cit., p. 19. La villa conserva aún algunos ejemplos aislados de casas nobles que atestiguan su pasado esplendor.

42. Quiles, art. cit., p. 149. 
herrero en un contrato de $1577^{43}$. Todos estos apellidos se corresponden con poblaciones y aldeas de la Tierra de Yanguas: Diustes, El Villar del Río, Villar de Maya, Vellosillo, La Mata, La Vega, Lería, La Cuesta, Valdecantos, San Andrés de San Pedro. Junto a ellos aparecen también numerosos apellidos de topónimos correspondientes a poblaciones de la vecina Rioja: Enciso y, sobre todo, Alfaro. Recuérdese que Yanguas formaba parte del Señorío de los Cameros y que perteneció al obispado de Calahorra-La Calzada hasta mediados del siglo XX. La pérdida del patronímico en favor del toponímico es un fenómeno habitual en la onomástica de la España del Siglo de Oro, sobre todo, por razones obvias, entre la población desplazada de sus solares de origen. Todo ello nos lleva a considerar como muy plausible que la familia del célebre impresor del Quijote fuera oriunda de la Tierra de Yanguas. Quizá incluso que esta villa soriana fuera la verdadera patria chica del editor, pues no en vano Yanguas había sido un núcleo de cierta importancia cultural medio siglo antes de la aparición del Quijote de la mano de la corte de los condes de Aguilar. El caso presentaría un cierto paralelismo con el del citado Antonio de Oncala, cuyo apellido indica un origen en la Tierra de Yanguas y al que hemos visto identificarse como «yangüés» en una de sus principales obras. De aceptarse esta hipótesis se entendería mejor aún la razón por la que Juan de la Cuesta consideró oportuno cambiar los protagonistas del famoso episodio de los arrieros y la incongruencia entre texto y epígrafes en la edición princeps.

\section{BIBLIOGRAFÍA}

AStrana Marín, Luis, Vida ejemplar y heroica de Miguel de Cervantes Saavedra, Madrid, 1948-1953.

AzPIAZU, José Antonio, «Los guipuzcoanos y Sevilla en la Alta Edad Moderna», Itsas 4, San Sebastián, 2003, pp. 207-225.

〈http://um.gipuzkoakultura.net/pdf/20\%20AZPIAZU.pdf〉.

BAENA, Julio, Discordancias cervantinas, Newark, Juan de la Cuesta, 2003.

Barroso Cabrera, Rafael y Morín de PABlos, Jorge. «A propósito de un "descuido cervantino": la alternancia yangüeses/gallegos en el Quijote», Cervantes 29.1, 2009, pp. 221-229.

〈http://www.h-net.org/ cervantes/csa/artics09/Barroso_MorinS09.pdf〉.

Beltrán Heredia, Vicente, Cartulario de la Universidad de Salamanca (1218-1600), tomo II, Acta Salmanticensia 19, Universidad de Salamanca, 1972.

CABello Hernandorena, Isidro, «El Quijote y La Rioja: el episodio de los yangüeses», Belezos: Revista de cultura popular y tradiciones de La Rioja 16, 2011, 49-55.

CAmporredondo, Luis, Miscelánea. Recuerdos de Yanguas, Soria, 1934.

CANAVAGgio, Jean, «Reseña a Francisco Rico. El texto del "Quijote". Preliminares a una ecdótica del Siglo de Oro», Criticón 99, 2007, 243-251.

Clemencín, Diego, El ingenioso hidalgo Don Quijote de la Mancha, Madrid, impr. E. Aguado, 1833.

43. La documentación ha sido publicada en: Toledo, op. cit., passim. 
De la Fuente AdÁneZ, Alfonso, Una exégesis para el siglo XVI: Antonio de Honcala (1484-1565) y su Comentario al Génesis, Biblioteca salmanticensis: Estudios, vol. 167, Salamanca, Universidad Pontificia, 1994.

Delgado Martínez, M. ${ }^{a}$ Consuelo, Apuntes sobre la vida rural de la Villa y Tierra de Yanguas (Soria). Siglos XII-XVI, Centro de Estudios Sorianos. CSIC, 1981.

EISENBERG, Daniel, «On Editing Don Quixote», Cervantes 3.1 (1983), 3-34.

ESPINOSA RUIZ, Urbano; UsERO, Luis M., «Eine Hirtenkultur im Umbruch. Untersuchungen zu einer Gruppe von Inschriften aus dem conventus Caesaraugustanus (Hispania Citerior)», Chiron 18, 1988, pp. 477-504.

GonZÁlez Ollé, Fernando (ed.) y Fernán LóPeZ De YANGUAS, Obras dramáticas, Madrid, Espasa-Calpe, 1967.

- Farsa Turquesana (1529?) ed. Julio F. Hernando y Javier Espejo, 2002 «ttp://parnaseo. uv.es/Lemir/Textos/FarsaTurquesana/Index.htm>.

- Triumphos de locura nuevamente compuestos por Hernán López de Yanguas 〈http:// parnaseo.uv.es/Lemir/Textos/Morbecq/Triumphos.htm>.

KLEIN, Julius, The Mesta. A Study in Spanish Economic History 1273-1836, Londres, 1920.

Martín Morán, José, El Quijote en ciernes y las fases de elaboración textual, Turín, Ed. Dell'Orso, 1990.

Navarro Blázquez, Alfonso, Ruta del Quijote en Sierra Morena, Memoria de Grado dir. Manuel Fernández Nieto, Facultad de Filología, Universidad Complutense de Madrid, 2007.

〈http://eprints.ucm.es/7761/1/T30142.pdf〉.

QUILES, Fernando, De yangüeses y otra gente en la conducta de plata (Sevilla, 1650-1675), en J. M. Almansa et al. (eds.), Actas del II Congreso Internacional del Barroco americano. Territorio, Arte, Espacio y Sociedad, Sevilla, 8 a 12 de octubre de 2001.

〈http://www.upo.es/depa/webdhuma/areas/arte/3cb/documentos/011f.pdf〉

Rico, Francisco (dir.), D. Quijote de la Mancha, Miguel de Cervantes, Madrid, Instituto Cervantes, 1998.

Rico, Francisco, El texto del Quijote. Preliminares de una ecdótica del Siglo de Oro, Barcelona, Destino, 2005.

RiQuer, Martín de, Don Quijote de la Mancha, Barcelona, Planeta, 1982.

RodríGuez Marín, Francisco, El Ingenioso hidalgo Don Quijote de la Mancha, Madrid, RABM, 1916.

Toledo Toledo, Manuel, Historia de la Villa y Tierra de Yanguas, Soria, 1995.

VAlDECANTOS, Diego, «Sobre el Quijote», Yanguas, 2005, pp. 13-14.

〈http://el-recreo.com/modulos/artsd.asp?id=291〉.

Recibido: 30 de agosto de 2011

Aceptado: 21 de noviembre de 2011 


\title{
Resumen
}

Abordamos en estas páginas el problema de la incongruencia entre texto y epígrafe de los capítulos X y XV del Quijote, desarrollando la hipótesis planteada en un artículo anterior sobre el mismo tema: el posible origen yangüés del editor Juan de la Cuesta como explicación del cambio del origen de los arrieros.

Palabras clave: Quijote, Juan de la Cuesta, arrieros, Yanguas.

Title: Again on Quixotes Yanguesans.

\begin{abstract}
Address in these pages the problem of incongruity between text and title of Chapters $\mathrm{X}$ and XV of Don Quixote, developing the hypothesis of an earlier article on the same topic: the possible Yanguesan origin of the editor Juan de la Cuesta as an explanation for the change of the origin of muleteers.
\end{abstract}

Key words: Quixote, Juan de la Cuesta, carriers, Yanguas. 